\title{
Designs of PCM based heat exchangers constructions for thermal energy storage tanks - examples and case study for selected design
}

\author{
Marta Kuta $^{1, *}$, Dominika Matuszewska ${ }^{1}$, Tadeusz Michał Wójcik ${ }^{1}$ \\ ${ }^{1}$ AGH University of Science and Technology, Department of Energy and Fuels, al. Mickiewicza 30, 30-059 Krakow, Poland
}

\begin{abstract}
Increasing energy consumption in residential and public buildings requires development of new technologies for thermal energy production and storage. One of possibilities for the second listed need is the use of phase change materials (PCMs). This work is focused on solutions in this area and consists of two parts. First one is focused on different designs of thermal energy storage (TES) tanks based on the phase change materials. The second part is the analysis of tests results for TES tank containing shelf and tube heat exchanger and filled with phase change material. Thermal energy storage tank is analyzed in order to use it in domestic heating and hot utility water installations. The aim of this research was to check the applicability of phase change material for mentioned purpose. Results show that using phase change materials for thermal energy storage can increase amount of stored heat. The use of properly selected PCM and heat exchanger enables the process of thermal energy storing and releasing to become more efficient.
\end{abstract}

\section{Introduction}

It is noticeable that continuous economic and social growth forces development of energy around the world, including Poland. Attention is focused not only on the electricity, but also on the production and storage of thermal energy.

It is particularly important to store heat in situation when amount of heat produced at a given moment by heating sources does not coincide with the current demand. Excess thermal energy can be stored and used later, when the needs are bigger. It enables the reduction of waste heat, limits additional heat production, it also has a positive impact on the environment and allows financial savings.

Many methods of thermal energy storage have been used over the years. One of them is based on the use of phase change materials (PCMs) and its latent heat. Phase change materials are substances characterized by the ability to store large amount of heat within small temperature range. This feature can be applied to store thermal energy or to regulate the ambient temperature. This paper will focus on the first option.

There are some requirements which have to be met for PCM based thermal energy storage systems. It is important to consider all problems related to phase change materials, such us: low thermal conductivity, changes in properties after many work cycles, changes in volume during the phase transition, possibility of corrosion during the contact with some materials. It is also important to select PCM suitable for the application, considering phase transition temperature range and enthalpy. Additionally it is possible to improve work of the system by design right heat exchanger's construction what is discussed in this paper.

\section{Thermal energy storage systems based on phase change materials - requirements, advantages and disadvantages of this type of solution}

Application of phase change materials has a great contribution to development of new thermal energy storage technologies and at the same point - reduction of waste heat and increasing the efficiency of using renewable energy sources. All requirements, phase change material characteristic, advantages and disadvantages should be taken into consideration at the design stage.

\subsection{Phase change materials}

\subsubsection{Phase change materials for low temperature TES systems}

Thermal energy storage with the use of phase change materials is based on the latent heat. It means that large amount of heat can be stored and released during the phase transition process at almost constant temperature.

Characteristics of PCM differs for material from organic (paraffins, polymers, alcohols, fatty acids), inorganic (i.e. salt, salt hydrates) and eutectics group. Phase change materials can be classified based on the type of the transition: solid-liquid, solid-solid, liquid-gas.

\footnotetext{
Corresponding author: marta.kuta@agh.edu.pl
} 
There are some proprieties required for PCMs used in TES systems[1, 2]:

- melting point according to the needs of the application - in this case suitable for central heating or hot water,

- high heat of fusion,

- high thermal conductivity in both phases,

- non-toxicity, non-flammability and lack of explosive properties during the normal use,

- compatibility with container material,

- small volume change during the transition,

- stability after many work cycles,

- small temperature difference between the melting and solidification points,

- reasonable price.

It is not possible to find material having all of the listed features, but it is important to choose one that meets the most important assumptions for the application.

\subsubsection{Phase change materials properties improvements}

Enhancement of thermal conductivity is one of the biggest challenge when it comes to PCM based applications. This parameter has to be analyzed and modified to improve process of charging and discharging thermal energy storage tanks filled with PCM.

There are some solutions investigated and applied for thermal conductivity improvement. Selected solutions used for PCM tanks are listed below:

- addition of high conductivity particles: silver, copper, aluminum, graphite, carbon nanotubes,

- incorporation of metal structures,

- macroencapsulation,

- heat exchanger designed taking into account all requirements.

In the next section selected designs of heat exchangers currently used in PCM based tanks and its advantages and disadvantages will be analyzed.

\section{Overview of different PCM based storage tank configurations}

\subsection{Examples of different heat exchangers designs}

Tay et al. [3] present results of experiment conducted on tube-in-tank filled with PCM for cold storage application. They compared tanks equipped with: one-, two- and four- tubes systems. Latent heat energy storage capacity slightly decreased with the increase of tubes amount, but at the same - time of melting process decreased as well (PCM melted faster). Both phenomena were related to the fact that tank parameters did not change, Authors concluded that the tube-in-tank design can deliver a high energy storage density.

Gil et al. [4] present experimental study of heat transfer enhancement of tube based storage tank. They compared two identical tanks equipped with tubes through which flows heat transfer fluid. One of them consists of 196 transversal squared fins and another one does not. Authors concluded that addition of fins can increase effectiveness of thermal conductivity between $4,11 \%$ and $25,83 \%$ for experiments with highest and lowest thermal power supplied to the PCM.

Ahmadi et al. [5] investigated spiral coil tube heat exchanger. They also performed numerical simulation to predict effect of changes of parameters like: tube parameters, spiral coil diameter, heat transfer fluid parameters. Authors concluded that spiral coil diameter plays an important role in melting process and heat transfer. It is possible to reduce total melting time up to $71.4 \%$ by increasing coil diameter from $50 \mathrm{~mm}$ to 70 $\mathrm{mm}$. They presented that tube diameter has little effect on melting process. They indicated that for larger spiral coil diameter, increasing tube diameter has opposite effect for reduction of melting time.

Kabbara et al. [6] studied experimentally latent heat energy storage system with coil - in -tank heat exchanger. They observed that natural convection played a significant role during the charging stage, but during the discharging stage the most important turned out to be conduction. They also found out that the inlet temperature of heat transfer fluid has bigger impact on system performance than heat transfer flow rates. They concluded that general thermal behavior of the PCM in tested tank is similar as for another published thermal storage geometries. However authors emphasize that heat transfer results for this specific geometry are valuable for future designs of PCM based heat exchangers and for establishing design rules for this kind of heat exchangers.

Prieto et al. [7] present results for thermal energy storage system based on PCM plate heat exchangers in comparison with a water tank. They are testing two different PCMs (Palmitic Acid and RT60 paraffin) characterized by similar transition temperature. This storage system is a part of micro - cogeneration system applied to the office space. The three TES systems were compared in terms of charges and discharges stages duration and in terms of the appropriate heat transfer rate. Authors concluded that the best system among considered in the research described in the paper is the one using Palmitic Acid. This system showed better performance during discharging, greater storage capability and lower cost for mCHP heating system. Authors did not indicated significant problems with this kind of heat exchanger design.

Guo et al. [8] present results of tests for direct contact thermal energy storage container. Authors commented that this kind of solution shows a good charging and discharging performance except the blocking by the deposited phase change material (PCM) at the initial stage of the charging process. They propose solution in the form of forming the quick channels with electric heaters and deal with the blocking issue. They concluded that results present that it is a good method to solve mentioned problem for the direct contact mobile thermal energy storage system, especially with a low rate of heat release. 
Kabbara and Abdallah [9] investigated phase change material based thermal energy storage system with PCM encapsulated in cylinders. They analyzed the system in terms of its storage capacity and the heat transfer rate to the PCM. Authors highlighted that inlet temperature was the most important parameter in this experiment. They concluded that there is evident that not all material inside tubes are melting and for further experiment there should be made some improvement in delivering heat to PCM from heat transfer fluid.

Solutions described above are only examples of designs used for thermal energy storage systems based on phase change materials. Fig. 1 presents graphically the appearance of exemplary heat exchangers designs described above and few additional.

\section{Experimental setup}

\subsection{Phase change materials}

The main assumption of the tests was the use of a PCM thermal energy storage system for hot water and lowtemperature heating. For this test purpose, commercially available organic PCM: CrodaTherm 53 has been used. Material used for tests is non-toxic, easily biodegradable and has low flammability. Figure 2 presents CrodaTherm53 before first phase transition, figure 3 presents material in liquid phase and figure 4 presents the appearance of the material after melting and after resolidification. PCM has initially the form of white gleaming flakes, after melting - dense, almost transparent liquid, after re-solidification it becomes white, solid block of material. Tests in smaller $(200 \mathrm{ml})$ and larger volume (60 1) did not show any problems with melting and solidification process (i.e. air voids).

Phase change transition temperature and heat storage capacity of this PCM specified by the manufacturer is respectively: $53^{\circ} \mathrm{C}$ (melting area), $51{ }^{\circ} \mathrm{C}$ (congealing area) and $226 \mathrm{~kJ} / \mathrm{kg}$. More properties of this PCM has been presented in table 1 .

Table 1 Properties of phase change material: CrodaTherm53.

\begin{tabular}{|l|c|}
\hline Properties & CrodaTherm53 \\
\hline Melting range, ${ }^{\circ} \mathrm{C}$ & 53 \\
\hline Congealing range, ${ }^{\circ} \mathrm{C}$ & 51 \\
\hline Heat storage capacity, $\mathrm{kJ} / \mathrm{kg}(\mathrm{kWh} / \mathrm{kg})$ & $226(0.062)$ \\
\hline Heat storage capacity, $\mathrm{kJ} / \mathrm{m}^{3}\left(\mathrm{kWh} / \mathrm{m}^{3}\right)$ & $187354(52)$ \\
\hline Density liquid, $\mathrm{kg} / \mathrm{m}^{3}$ & 829 \\
\hline Density solid $\mathrm{kg} / \mathrm{m}^{3}$ & - \\
\hline Heat conductivity (liquid), $\mathrm{W} /(\mathrm{m} \cdot \mathrm{K})$ & 0.16 \\
\hline Heat conductivity (solid), $\mathrm{W} /(\mathrm{m} \cdot \mathrm{K})$ & 0.28 \\
\hline
\end{tabular}

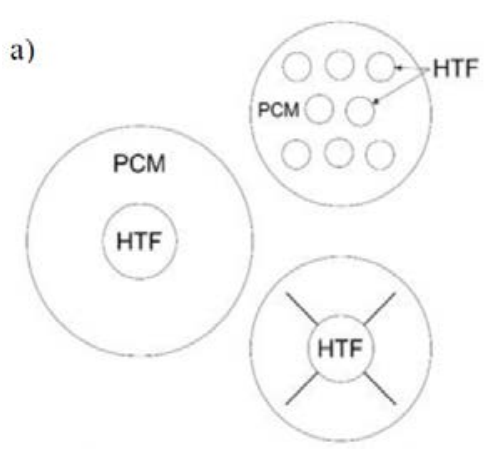

b)
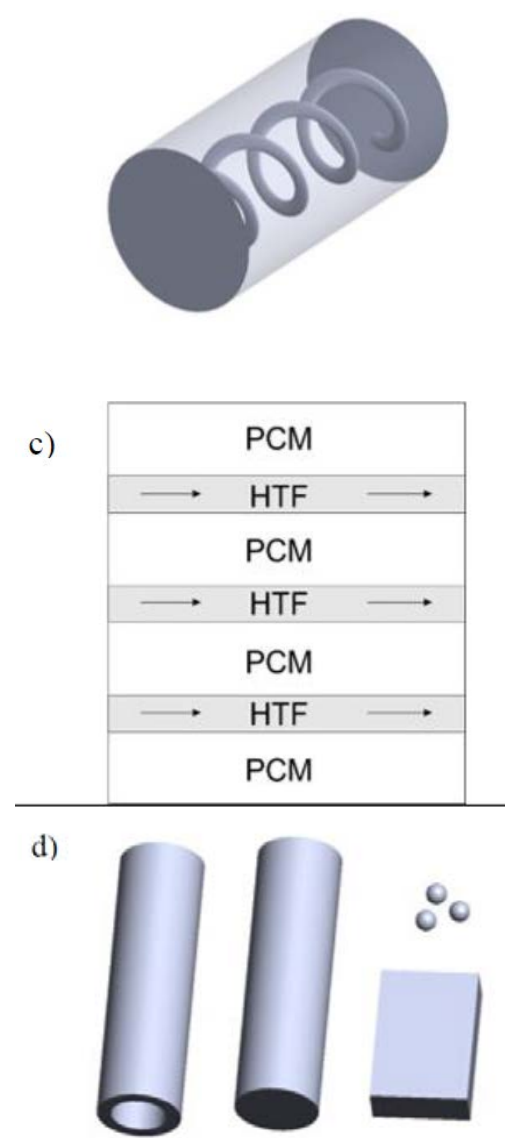

Fig. 1. Examples of PCM based heat exchangers : a) tube based storage tank (shell and tube,tube with fins heat exchangers): b) spiral coil tube heat exchanger, c) PCM plate heat exchanger, d) capsules filled with PCM ;HTF -heat transfer fluid.

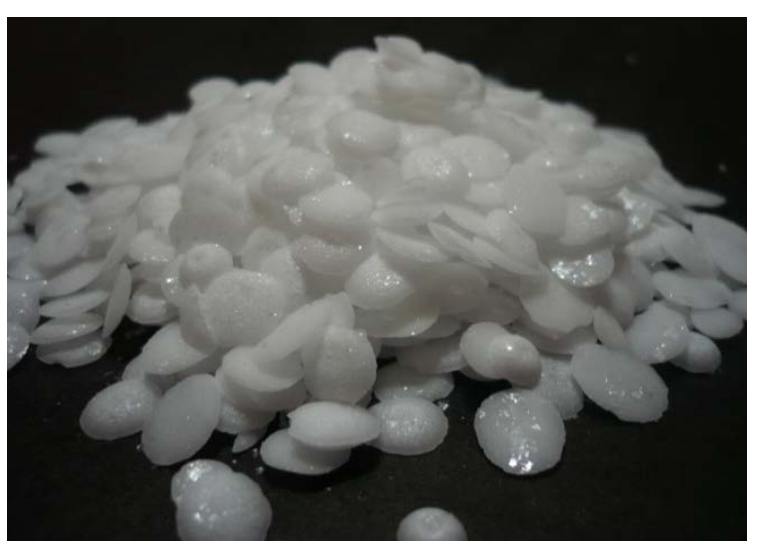

Fig. 2. CrodaTherm53 before first phase transition. 


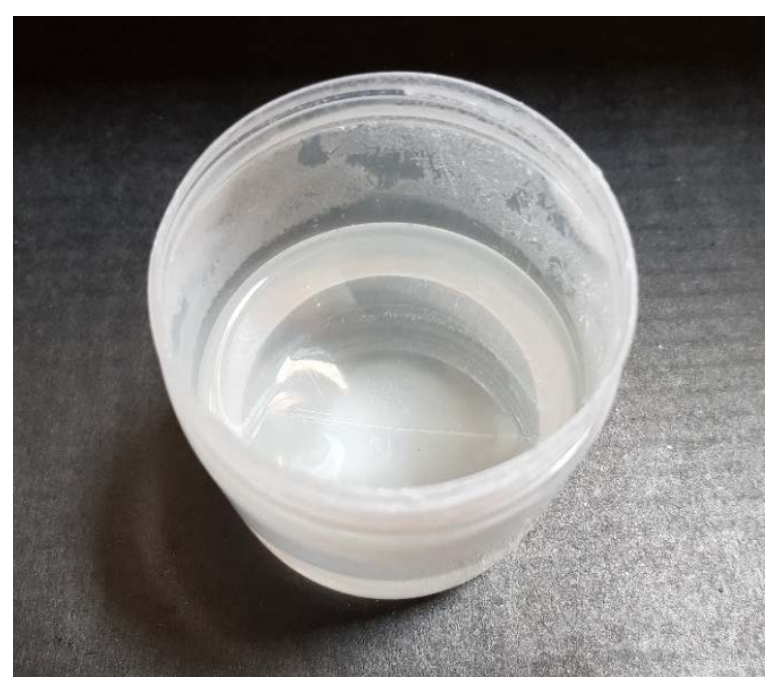

Fig. 3. CrodaTherm53 after melting - liquid phase.

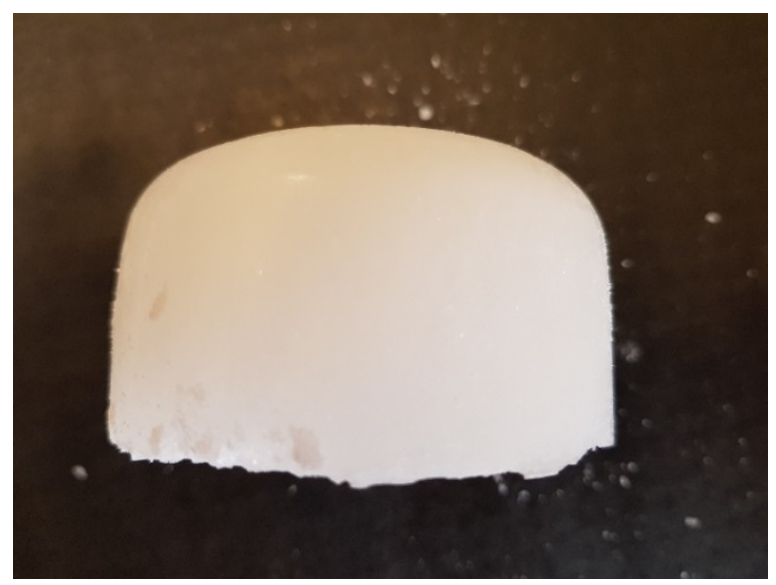

Fig. 4. CrodaTherm53 after re-solidification - solid phase.

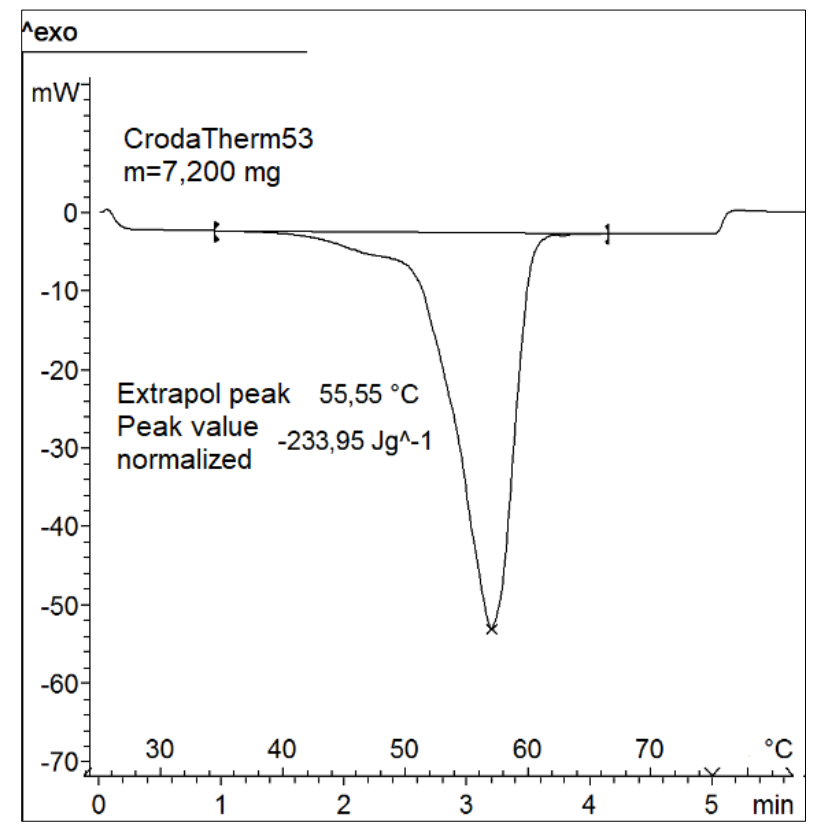

Fig. 5. DSC curve for CrodaTherm 53 - melting.

Figure 5 and 6 present results of the measurements made with the use of differential scanning calorimeter (DSC) for CrodaTherm 53: Fig. 5 - melting stage and Fig. 6: solidification stage. The DSC analysis shows that the transition temperature is around $55^{\circ} \mathrm{C}$ for melting and for congealing is a few degrees lower. (Data sheet: $\mathrm{T}_{\text {melting }}=$ $53^{\circ} \mathrm{C}, \mathrm{T}_{\text {Congealing }}=51^{\circ} \mathrm{C}$. The phase change heat approx. $230 \mathrm{~kJ} / \mathrm{kg}$ (data sheets: $225 \mathrm{~kJ} / \mathrm{kg}$ ). Obtained results are similar to data indicated in the product sheet.

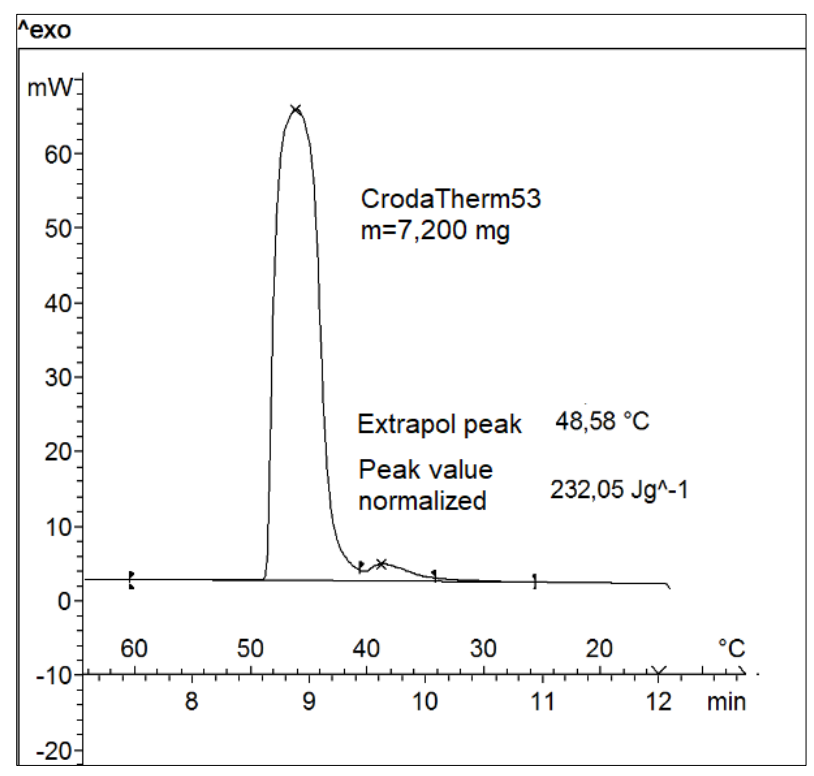

Fig. 6. DSC curve for CrodaTherm 53 - solidification.

\subsection{Test rig description}

Test rig consists of thermal energy storage tank filled with water with nominal capacity $200 \mathrm{l}$. Its general view has been presented in Fig. 7. The tank is made of steel with a thickness of $5 \mathrm{~mm}$, protected against corrosion. It is possible to open the tank to place an insert filled with phase-changing material inside it. The tank is equipped with measuring connectors (PT 100, B class) which allow temperature measurement inside both - the magazine and the insert. Measuring connectors were distributed along the length and breadth of the tank and insert to allow observation of the temperature distribution in both the central and the external parts of the tank and insert. Figure 8 presents the insert - shell and tube heat exchanger. It is made of steel and has a system of 26 steel pipes with a diameter of $25 \mathrm{~mm}$. For testing purposes $80 \%$ of its volume has been filled with PCM (60 1).

The test rig is powered by a heating system based on a $10 \mathrm{~kW}$ flow-through electric heater. The flow of heat transfer fluid (in this case - water) is forced by a circulation pump. Heating system is located in an electrical box attached to the tank. Measurement data is automatically downloaded and saved at 2-minute intervals using a data acquisition system. 


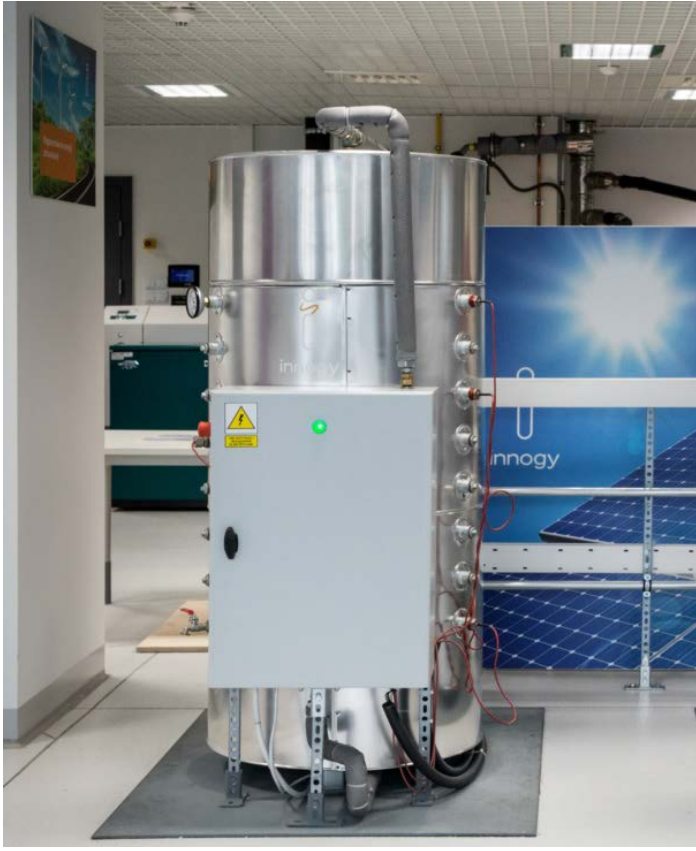

Fig. 7. Thermal energy storage tank.

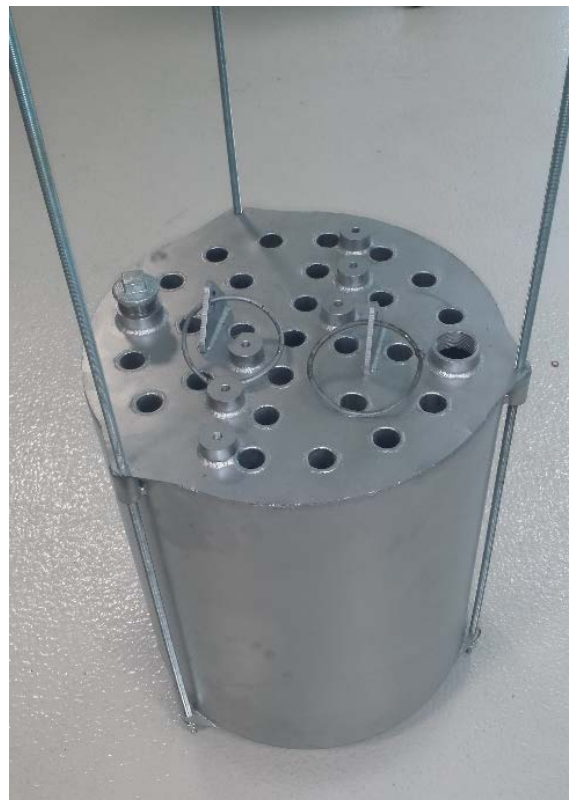

Fig. 8. PCM based insert for thermal energy storage tank.

\section{Results and discussion}

Figure 9 and 10 present comparison of temperature curve for a TES tank containing empty PCM cartridge and exactly the same tank, but containing 601 of PCM: CrodaTherm53. Figure 9 presents the heating stage. It can be observed that heating process for tank filled with PCM runs much slower (about 6 times in the temperature range: $30-65^{\circ} \mathrm{C}$ ). It is related to $\mathrm{PCM}$ phase transition which can be observed in the temperature range: $51-55^{\circ} \mathrm{C}$.

Figure 10 presents cooling stage. Also in this case, the flattening of the temperature curve in the area of 51 $55^{\circ} \mathrm{C}$ can be observed. The heat dissipation from the tank runs smoothly.

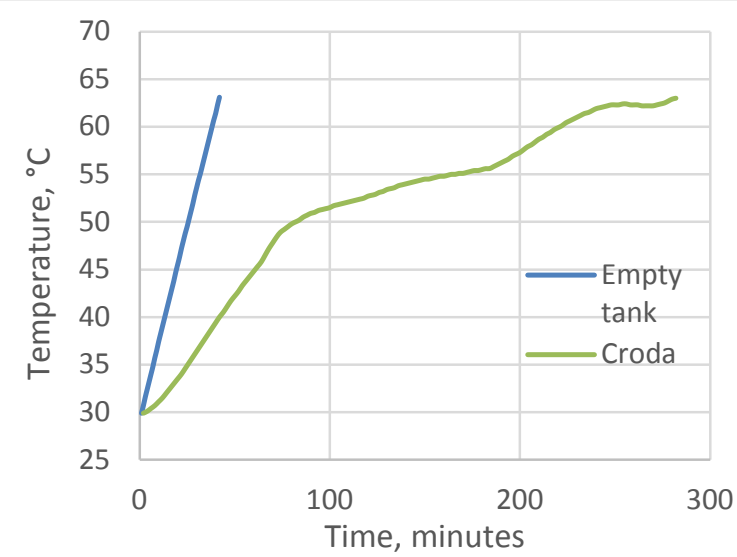

Fig. 9. Heating process for empty tank and tank with PCM insert; Measuring connectors located in the middle of the tank and in the middle of the insert.

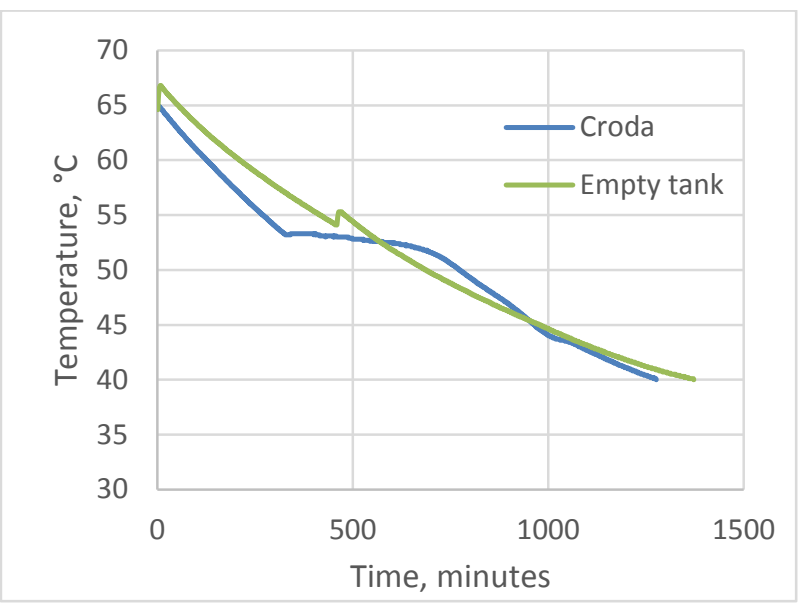

Fig. 10. Cooling process for empty tank and tank with PCM insert; Measuring connectors located in the middle of the tank and in the middle of the insert.

Figure 11 and 12 present comparison of results for heating stage (Fig.11) and cooling stage (Fig.12) for the tank consist of PCM-insert. Temperatures in three parts of the insert are presented on the diagram: temperature next to the left wall, next to the right wall and in the middle of the insert. There is also presented the temperature of the water inside the tank, flowing around the PCM insert. It can be observed in the Fig. 11 that temperature of the water started decreasing after turning the heater off. When temperature was close to $50^{\circ} \mathrm{C}$, the heater has been turned on. This process has been repeat one more time to enable observation of the efficiency of heat transfer from water to phase change material. It can be observed that transition occurs in a similar way in the entire insert. Curves for all analyzed points - the center and both walls run similarly and they follow the water curve. When the temperature of $55^{\circ} \mathrm{C}$ is exceeded, the PCM temperature starts to rise quickly and evenly with the water temperature - this is the information that phase transition occurred and PCM in the form of liquid is storing sensible heat.

Figure 12 presents cooling process for the points discussed above - left wall, right wall and the middle of the insert. It can be observed that PCM release heat 
efficiently. Water temperature curve runs close to PCM temperatures.

Results shows that heat is stored evenly throughout the PCM - insert.

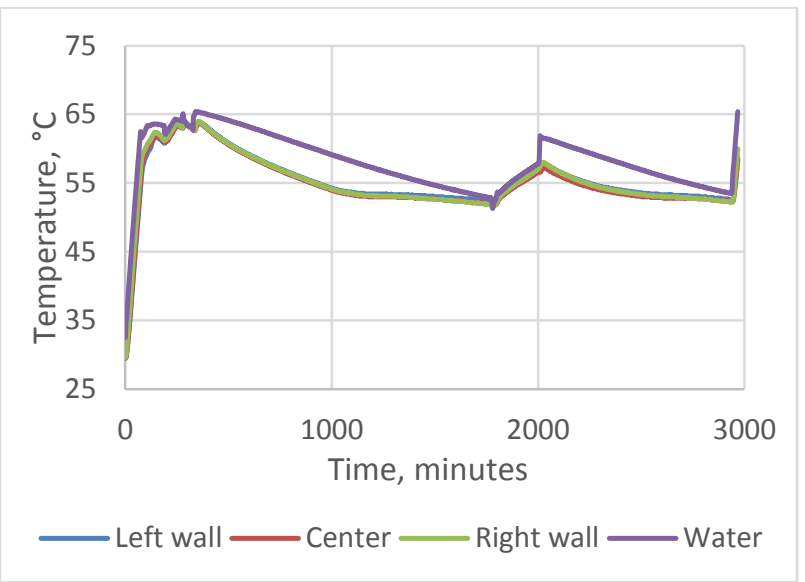

Fig. 11. Temperature distribution inside the tank - heating.

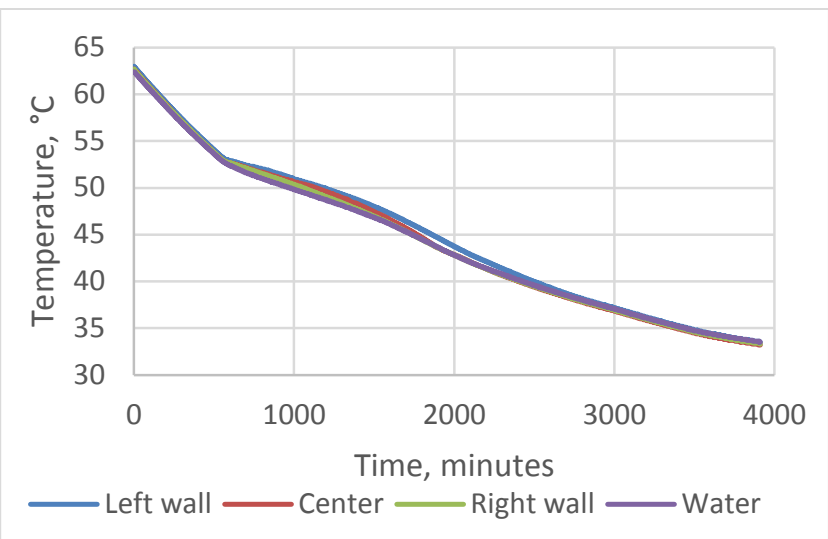

Fig. 12. Temperature distribution inside the tank - cooling.

\section{Conclusions}

This paper presents examples of PCM based heat exchangers applied for thermal energy storage tanks with its advantages and disadvantages. Analysis shows that heat exchanger has to be designed based on its application and used phase change materials. Many aspects need to be considered, for example: required temperature, used PCM (organic/inorganic), heat release time, volume of PCM. This paper presents also results from experimental study of shell and tube heat exchanger used for 200 - litres thermal energy storage tank. Results shows that:

- It is possible to use phase change materials to modify TES tank and achieve better results - store more heat in the same volume.

- Using shell and tube heat exchanger enables efficient supply of heat to the entire volume of PCM.

- Phase change material CrodaTherm 53 responds to the requirements of quick heat transfer when used with an appropriate heat exchanger.
- Test results for PCM do not differ significantly from the information provided by phase change materials manufacturer.

- In order to store large amounts of heat, the tested inset should be replaced with a larger one - fully filling the tank or heat exchanger tubes should be installed directly in the tank and tank should be filled with PCM.

The aim of the research has been successfully accomplished, but it was also observed that there is still a large area to be developed in the area of PCM based heat exchangers (related to both: construction of heat exchanger and properties of PCM).

\section{Acknowledgements}

Authors would like to express the gratitude to innogy Polska S.A. for the opportunity to perform research at the AGH INNOGY STORAGE LAB located at the AGH UST Center of Energy.

This work was supported by AGH - University of Science and Technology (Project 11.11.210.376).

\section{References}

1. A. Sharma, V.V Tyagi, C.R. Chen, D. Buddhi, Renewable and Sustainable Energy Reviews 13, 318-345 (2009)

2. D. Fernandes, F. Pitié, G. Cáceres, J. Baeyens, Energy 39, 246-257 (2012)

3. N.H.S. Tay, M. Belusko, F.Bruno, Applied Energy 90, 288-297 (2012)

4. A. Gil, G. Peiró, E. Oró, L.F. Cabeza, Applied Thermal Engineering 142, 736-744 (2018)

5. R. Ahmadi, M.J. Hosseini, A.A. Ranjbar, R. Bahrampoury, Sustainable Cities and Society 38, 145-157 (2018)

6. M. Kabbara, D. Groulx, A. Joseph, International Journal of Thermal Sciences 130, 395-405 (2018)

7. M.M. Prieto, B. Gonzalez, E. Granado, Energy and Buildings 122, 89-97 (2016)

8. S. Guo, J. Zhao, W. Wang, G. Jin, X. Q.An. Wang, W. Gao, Applied Thermal Engineering 78, 556-564 (2015)

9. M.J. Kabbara, N.B. Abdallah, Procedia Computer Science 19, 694-701 (2013) 